\title{
Food Production: The Critical Role of Irrigation Water
}

\author{
Khem Raj Sharma
}

Abstract: As food need rises, Nepal's reliance on irrigated agriculture does increase. Increased production to satisfy the food demand of the future must essentially come from intensification, not from expansion of agriculture. Intensification potential of irrigated agriculture is much higher than rainfed system. Technologies, professionals and farmers should go together to achieve greater impacts and ensure the country's food security.

Key words: Irrigated agriculture, food security, farmer participation, conjunctive use, physical infrastructure, integrated water resource management, Nepal

A bout $70 \%$ of the freshwater worldwide is used for agriculture, $20 \%$ for industry and $10 \%$ for domestic use. In Nepal, domestic and industrial water use accounts for a minimal percentage compared with $90 \%$ of total water use in the irrigation sector. The current population is over 25 million, and is projected to reach 41 million by 2025 . With this increase in population, the demand for water for drinking, agriculture, industry, power generation and other uses will increase. The water requirements for hydropower generation, however, are difficult to estimate, though all large-scale hydropower generation plants require large quantities of water. The increased demand for water in different sectors will have to be met by proper planning and the lion's share presently proportioned to irrigation will have to be reduced to a level as low as the global average.

With this scenario of water demand, the nation's food production and demand outlook should be reviewed. Nepal as a whole is a food deficit country and it is projected that a two-fold increase in food production will be required in the country by the year 2025. For several reasons the rate of increase in food production so far is less than anticipated. First, the area actually irrigated is too little and cropping intensities are low. Secondly, large areas continue to be planted in traditional low-yielding crop varieties. Also, the appropriate management technologies are not readily available. Even the procurement and distribution of chemical fertilizers are badly managed. To add to the problem, the nation's agricultural area is being reduced by urbanization.

\section{Food security}

In the recent past prices of basic food items like rice, wheat flour and cooking oil have increased sharply. Food stocks of poor households in 38 districts have been reduced by half because of increased food prices. The mid-west and far-west regions of the country have been hit the hardest. The problem is also an offshoot of the general price rise at the international level. The increased fuel prices making the cost of agricultural productipn high, the adverse impacts of climate change on crop productivity, the conversion of food crops into bio-fuel and the demand for luxury food by the higher middle class families, especially in India and China, are considered as the main factors responsible for increased food prices.

Due to the high cost of production, domestic production cannot compete with imported food from India. As a result, Indian food stuffs are dominating Nepal's markets. The danger of this dependence is now evident as India has banned export of basic staple foods like rice and wheat.

Because of the agrarian nature of economy (about $80 \%$ of the people have agriculture as the main occupation) and the shortage of food items, Nepal has no choice but to increase its agricultural production by enhancing the land and irrigation water productivity.

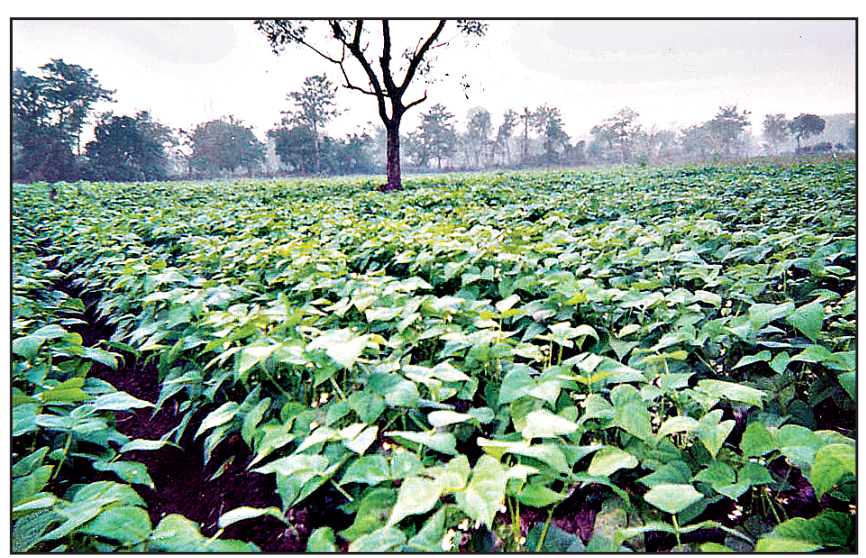

An Irrigated farm

\section{Irrigation potential and development}

Out of the total of 2.641 million hectares of cultivated land, Nepal's irrigation potential with conventional irrigation technologies is said to be 1.766 million ha. Available figures indicate that by the end of the 10th Plan, in July 2007, about 1.195 million ha (67\%) had already got some form of irrigation infrastructures facilities. This shows that there is a scope for an increase of about 0.570 million ha in the irrigated area in the country. Additional area could also be provided with irrigation water by adopting non-conventional 
irrigation technologies such as micro-irrigation and rainwater harvesting.

Productivity in many irrigation areas, however, has been disappointing and the sustainability of many schemes is threatened because of financial viability. Irrigation fees from water distribution has proven to be difficult to collect. And public funding for operation and maintenance is not adequate.

The paradox is also that large investments continue to be made in new or rehabilitated irrigation system infrastructure, rather than in making existing systems perform better. This is due to a combination of factors including the availability and ease of administration of loans in certain categories preferred by the international funding community, the desire of engineers and politicians to build the physical infrastructure rather than do the more difficult training of system personnel and farmers, and the fact that construction is always more lucrative than are operations and maintenance activities.

The Water Resources Strategy and National Water Plan have fixed targets with regard to expansion of irrigated areas and the improvement of the performance of existing irrigation systems. As a departure from the previous approach the plans are to be made following the principles of integrated water resources management (IWRM). However, the action programs as reflected in the current 3-year interim plan are not specific in addressing the approach and principles in realizing the concept of IWRM. Also, focus should have been laid in the assurance of year round irrigation which the plan fails to address.

\section{Irrigation management}

Because it is two times more productive than rainfed agriculture, our reliance on irrigated agriculture has increased. As we cannot expect to have more share of water in irrigation at the cost of power generation, industrial use and domestic supplies, the only viable irrigation alternative left is to improve our management - this time the management of water. In other words, we have to produce more food grains with the less use of irrigation water.

Little is known about water management requirements or about the effects of water shortage on food-grain corps. Due to limited water supply in the source of many irrigation systems, especially in the non-rainy season, expansion of irrigated areas in existing irrigation systems must come from savings derived from good water management. For this, some of the water efficient technologies already developed by researchers and farmers could be very useful. In the Terai, conjunctive management of surface and ground waters is a promising option.

\section{Approaches for adaptation}

There are three promising approaches to the problem focused on improvements in the physical, biological, and management aspects.

\section{Physical approach}

Improvements in physical infrastructure requires the establishment of irrigation system facilities, and focuses on converting rainfed land to irrigation as well as the rehabilitation of existing irrigation facilities; thus extracting more of the potential of both land and water resources. As most of the easily tappable water sources have been diverted, the need is to go for more expensive sites. In a cash poor country like Nepal this option is relatively less feasible.

\section{Biological approach:}

This approach focuses on improvements in the selection of genetic varieties and cultivation techniques at the field level. For example, irrigated rice and wheat yield potential can be increased by 30 to $40 \%$. Hybrid varieties have even more potential. This is the biological approach to increasing agricultural production. There is tremendous potential in this aspect.

\section{Management approach}

The improvement of irrigation system management for growing more food will cost only a nominal amount in operation and maintenance expenses per hectare per year. It can very easily result in increased outputs of about 1.5 ton per hectare per year.

Given these adaptations, a single approach or a combination of two or more approaches is required for increasing food production to meet the needs of the country. Among the three, the improved management approach is the more reasonable and realistic for Nepal.

Technology, professionals and farmers are the prominent factors and they should be made to go handin-hand for a good managerial approach. To start with, we need a management revolution for the irrigation sector and for increased agricultural production this should gradually encompass the whole agricultural sector. In our neighboring countries the green revolution was in fact a management revolution in the agricultural sector. Production inputs management, like improved seeds, fertilizer, pest control and water, were introduced as a package deal. As a result, China and India are self sufficient in their food grains requirement.

Usually, obtaining a reliable water supply from the system is a major problem and farmers have limited freedom in on-farm water management until the water supply situation is solved first. So far, this issue has not been adequately addressed.

In the Agriculture Perspective Plan (APP), much emphasis has been given to the exploitation of Nepal's groundwater reserve. There are reports indicating that much of the Terai area under cultivation can be 
irrigated by groundwater. Shallow tubewells are taken as the remedy of our outstanding problems. If this is taken as a breakthrough in general, one shallow tubewell will have to be installed at an interval of every $164 \mathrm{~m}$. If this should be implemented, questions will arise about its sustainability in terms of technicalities in the indiscriminate use of groundwater, the availability of the pumps and other equipments in the country, as well as the operation and maintenance costs that will be incurred. Focus should therefore be laid on irrigating more area depending on the water discharge from a tubewell.

The best approach is to go for balanced use of both surface water and groundwater. This will avoid the overuse of groundwater, which can be used as an insurance against droughts and dry spells. Moreover, clear and sustainable groundwater rights should be established by the state before developing the irrigation infrastructure. Installation of tubewells incompatible with water rights and local management capacities is bound to create conflicts among the users in one hand, and between the beneficiaries and the agencies on the other.

Questions are arising about the sustainability of the irrigation systems that have been already developed. This is the outcome of the dependency syndrome created from a lack of farmer participation during system planning and development. Clear and recognized management responsibility and authority is lacking. For efficient management, adequate financial and human resources are essential and this aspect has been overlooked. Accountability for management should commensurate with incentives. This should be on an institutional basis rather than the individualistic approach that is generally followed.

\section{Farmers' perspectives}

On a wider scale, our production systems and irrigation infrastructures are under-performing because of the issues raised above. Over and over again capital investments have been made in various forms of rehabilitation and maintenance as a remedy to the problems. Farmers participation and their capability to generate and mobilize resources have come as slogans without giving due regard to local management. In the name of peoples 'participation' much is expected from poor farmers. Have we ever analyzed how long a farmer is engaged on running his farm to make a living for his family? How capable he is and how far can be improve? Do farmers perceive the problems the same way the agencies perceive them? What will be the processes to make farmers' association more viable? These are some of the questions that planners should address while establishing a sustainable management continuum.

Policy makers should sometimes imagine themselves as farmers. Consider, for example, an irrigation system. The farmers are told by government officials that management of the system is to be turned over to them. The government will rehabilitate the system but they, too, will have to shoulder part of the expense. The farmer is not fully convinced because he does not have faith in the government officials. In such a situation, what is required is a convincing answer that the farmer will have water supply to the system and to his farm during the times of need, that he will be asked to pay water fees provided he gets water in his fields and that equity will be maintained to avoid disputes. Improved water allocation and distribution in the canals could improve service delivery and water use efficiency in the system as well as water distribution equity among farmers. In most irrigation systems, however, management improvements can be made by avoiding inadequacies in terms of design and institution building. Equity in land and water distribution need to ensure to make an irrigation system pro-poor.

Khem Raj Sharma, is an agricultural engineer and works for Nepal's Department of Irrigation. Dr Sharma is specialized in land and water resources management and has working experience from Cambodia, Bangladesh and India. In Nepal, he worked as the Coordinator of Nepal Irrigation Sector Project and On-farm Water Management Program. He was engineer-in-charge of the Integrated Hill Development Project and the Hill Food Production Project. He has authored two books and has presented numerous scientific papers in national and international forums. He was chief editor of Irrigation Newsletter and Sichai Gatibidhi, and has taught and guided engineering students in their thesis.

Corresponding address: khemraj.sharma@gmail.com. 